\section{OAK RIDGE $\mathrm{Y}-12$ PLANT}

UNION CARBIDE

\section{USE OF THE LASER INTERFEROMETER FOR POSITION FEEDBACK}

W. E. Barkman

\section{MASTER}

October 1979
OPERATED BY

UNION CARBIDE CORPORATION FOR THE UNITED STATES DEPARTMENT OF ENERGY 


\section{DISCLAIMER}

This report was prepared as an account of work sponsored by an agency of the United States Government. Neither the United States Government nor any agency Thereof, nor any of their employees, makes any warranty, express or implied, or assumes any legal liability or responsibility for the accuracy, completeness, or usefulness of any information, apparatus, product, or process disclosed, or represents that its use would not infringe privately owned rights. Reference herein to any specific commercial product, process, or service by trade name, trademark, manufacturer, or otherwise does not necessarily constitute or imply its endorsement, recommendation, or favoring by the United States Government or any agency thereof. The views and opinions of authors expressed herein do not necessarily state or reflect those of the United States Government or any agency thereof. 


\section{DISCLAIMER}

Portions of this document may be illegible in electronic image products. Images are produced from the best available original document. 
Reference to a company or product name does not imply approval or recommendation of the product by Union Carbide Corporation or the Department of Energy to the exclusion of others that may meet specifications.

Printed in the United States of America. Available from

National Technical Information Service

U.S. Department of Commerce

5285 Port Royal Road, Springfield, Virginia 22161

Price: Printed Copy A02; Microfiche A01

This report was prepared as an account of work sponsored by an agency of the United States Government. Neither the United States Government nor any agency thereof, nor any of their employees, nor any of their contractors, subcontractors, or their employees, makes any warranty, express or implied, nor assumes any legal liability or responsibility for any third party's use or the results of such use of any information, apparatus, product or process disclosed in this report, nor represents that its use by such third party would not infringe privately owned rights. 
Distribution Category: UC-38

\title{
USE OF THE LASER INTERFEROMETER FOR POSITION FEEDBACK
}

\author{
W. E. Barkman
}

Fabrication Eystcm3 Deportmeat

$Y-12$ Development Division

Submitted to Working Group 3, Machine Tool Controls, of DoD Machine Tool Task Force Project, administered by Lawrence Livermore Laboratory for Air Force Materials Laboratory under Project Order WAL 8-5089.

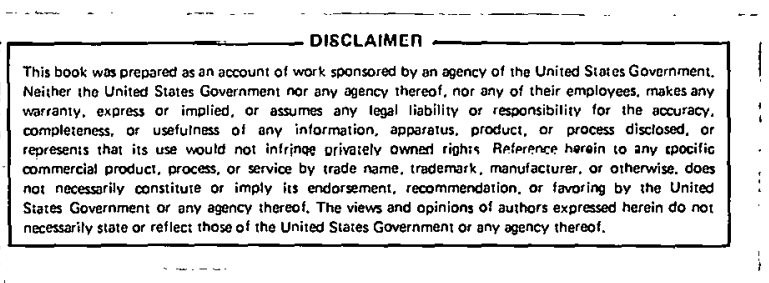

Oak Ridge Y-12 Plant

P. O. Box Y, Dak Ridge, Tennessee 37830

Prepared for the Department of Energy Under US Government Contract W-7405-eng-26 
Date of Issue: October 19; 1979

Distribution Category: UC-38

\title{
USE OF THE LASER INTERFEROMETER FOR POSITION FEEDBACK
}

\author{
W. E. Barkman
}

Fabrication Systems Department

Y-12 Development Division

\begin{abstract}
Submitted to Working Group 3, Machine Tool Controls, of DoD Machine Tool Task Force Project, administered by Lawrence Livermore Laboratory for Air Force Matcrials Laboratory under Project Order WAL 8-5089.
\end{abstract}

Oak Ridge Y-12 Plant

P. O. Box Y, Oak Ridge, Tennessee 37830

Prepared for the Department of Energy Under US Government Contract W-7405-eng-26 


\begin{abstract}
Traditional methods for monitoring the position of machine-tool slides have utilized resolvers, encoders, Inductosyns, etc, that typically infer the position of the cutting tool and part by measuring a secondary characteristic such as the angle of a drive motor or lead screw. Some undesirable features of this technique arise from the lack of rigidity between the point of interest and the point of the measurement. Other disadvantages result from the resolution and accuracy associated with these transducers. The laser interferometer position-measuring systems available today offer \pm 0.5 parts-per-million (ppm) accuracy with a maximum measuring velocity of $18 \mathrm{~m} / \mathrm{min}(720 \mathrm{in} / \mathrm{min})$ and permit the user to measure more directly the location of the point of interest. The use of laser position-measuring systems on a variety of machine tools is discussed.
\end{abstract}




\section{CONTENTS}

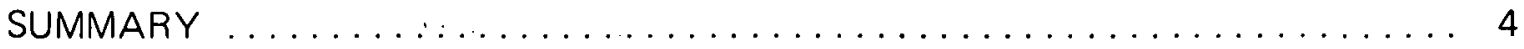

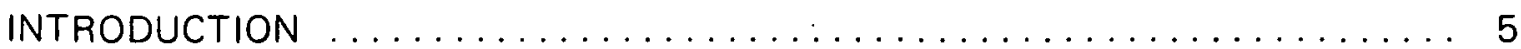

THE LASER INTERFEROMETER ...................... 6

APPLICATIONS FOR LASER FEEDBACK $\ldots \ldots \ldots \ldots \ldots \ldots \ldots \ldots \ldots \ldots$

CONCLUSIONS ............................... 14 


\section{SUMMARY}

Machine-tool manufacturers have traditionally used position-feedback devices such as resolvers, encoders, Inductosyns, etc, to provide slide-displacement data to the control servo system. The location of the cutting tool and workpiece are thereby inferred by measuring a secondary characteristic such as the angle of the motor drive shaft or lead screw. Undesirable features of this technique arise from unstable elements that are outside the measurement loop as. well as from inherent accuracy considerations. The laser interferometer position-measuring system offers an accuracy that is unsurpassed by conventional feedback systems; and, while it is more expensive, it should represent only a small fraction of the total cost of a precision, numerically controlled machine tool. Also, it is frequently possible to measure more closely the location of the cutting tool and workpiece from a common reference, thereby avoiding some potential thermal-instability problems. This report discusses several laser-feedback applications ranging from a manual inspection machine to a large-component diamond-turning lathe that is used to fabricate optical components for the Los Alamos Scientific Laboratory Laser Program. 


\section{INTRODUCTION}

Closed-position-loop servo systems are standard features of modern continuous-path numerical controls $(\mathrm{NC})$ used with today's machine tools. While traditional methods for monitoring the position of the machine slides have utilized resolvers, encoders, Inductosyns, etc, it is recognized that these techniques only infer the position of the cutting tool and workpiece by measuring a secondary characteristic such as the angle of a motor drive shaft or lead screw. Undesirable features of such systems include lack of rigidity between the point of interest and the point of measurement, Abbé offsets, and inherent accuracy limitations. The laser interferometer position measuring systems in use at the Oak Ridge Y-12 Plant ${ }^{(a)}$ offer a \pm 0.5 parts-per-million (ppm) accuracy with measurement velocities of $18 \mathrm{~m} / \mathrm{min}(720 \mathrm{in} / \mathrm{min})$ and permit the user to measure more directly the location of the cutting tool. The following sections of this report will discuss briefly the Hewlett-Packard Company laser interferometer and give examples of machine systems utilizing laser interferometers for position feedback.

(a) Operated by the Union Carbide Corporation's Nuclear Division for the Department of Energy. 


\section{THE LASER INTERFEROMETER}

The Hewlett-Packard Company's helium-neon laser interferometer utilizes the phase variations of an alternating-current $(A C)$ wave form to provide position information. This mode of operation means that the system is less susceptible than previous direct-current (DC) lasers to environmental factors such as dust or smoke that might attenuate the intensity of the laser beam. In addition, measurement resolution can be extended by factors up to $40 X$ (higher under ideal conditions) through electronic frequency-multiplication techniques.

The AC laser system utilizes one laser source that can be used for as many as six simultaneous measurements on a multiaxis machine through the use of various combinations of beam splitters and beam benders. However, all configurations must have the basic measurement optics; ie, the fixed and moving optical components that determine the actual measurement path. Of the various units available, the standard interferometer is the least expensive and is used with a cube corner retroreflector. Other optical elements that can be used for various applications include the single-beam interferometer and the plane-mirror interferometer. Focusing optics may also be used as needed.

Displacement output signals in the form of up/down pulses, A-quad-B pulses, or both, are available for interfacing the laser to the NC. Typically, the laser system can be interfaced using the encoder-feedback option available with most NCs, although it may be necessary to provide an auxiliary form of velocity feedback if a tachometer is not used with the drive system. This can be accomplished inexpensively using frequency-to-voltage (F/V) converters as shown in Figure 1.

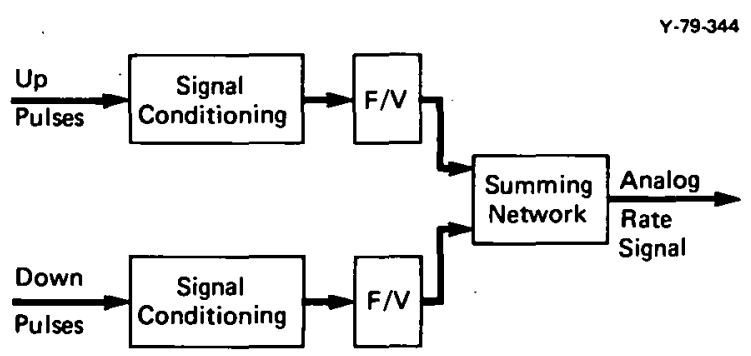

Figure 1. VELOCITY SIGNAL GENERATION USING LASER UP/DOWN PULSE OUTPUT AND FREQUENTY-TO-VOLTAGE (F/V) CONVERTERS.

Another factor to be considered is the requirement for velocity of light compensation. Since the index of refraction of air is a function of temperature, pressure, and humidity, it is necessary to monitor changes in these parameters and adjust the output data accordingly. Manual wavelength compensation can be accomplished after determining the necessary environmental conditions, or an automatic compensator may be used. Hewlett-Packard offers an automatic-compensation option that senses periodically the environmental conditions and determines the necessary correction. Unfortunately, use of this option also degrades the system accuracy to $\pm 1.5 \mathrm{ppm}$ (a special option can be utilized to improve the compensation accuracy to $\pm 0.7 \mathrm{ppm}$ ). Farrand Industries, Inc offers an electronics/optics package that senses changes in a fixed-length path and establishes the compensation accordingly without degrading the system accuracy.

Other sources of error include air-temperature gradients, part temperature, laser alignment, and dead path. While wavelength of light compensation can be utilized to adjust for changes in the refractive index, it is necessary that the beam path be protected from temperature gradients. Alternatively, the air path can be well mixed as a result of turbulence from a fan 
or other external device. Part temperature can cause problems also if the workpiece is fabricated at one temperature and inspected or used at another temperature. This error can be reduced by adding extra compensation to the value calculated previously for the refractive index of air, or the part can be machined at a known temperature such as $20^{\circ} \mathrm{C}$ $\left(68^{\circ} \mathrm{F}\right)$. Dead-path error is introduced because of an uncompensated length of laser light between the interferometer and the reflector when these optical elements are at their closest positions. The velocity of light compensation provides an adjustment for the refractive index of the air path encompassed by the slide travel, but additional compensation is required for the dead path. In addition, the dead path itself should be minimized by mounting, as closely together as possible, the interferometer and the reflector at their "nearest" positions. Finally, the laser-beam alignment should be carefully performed to avoid cosine errors. 


\section{APPLICATIONS FOR LASER FEEDBACK}

In its simplest application the laser interferometer provides position-feedback information to an operator in order that manual adjustments can be made to a machine. One example of this type of operation is the laser interferometer sweep gage shown in Figure 2. This

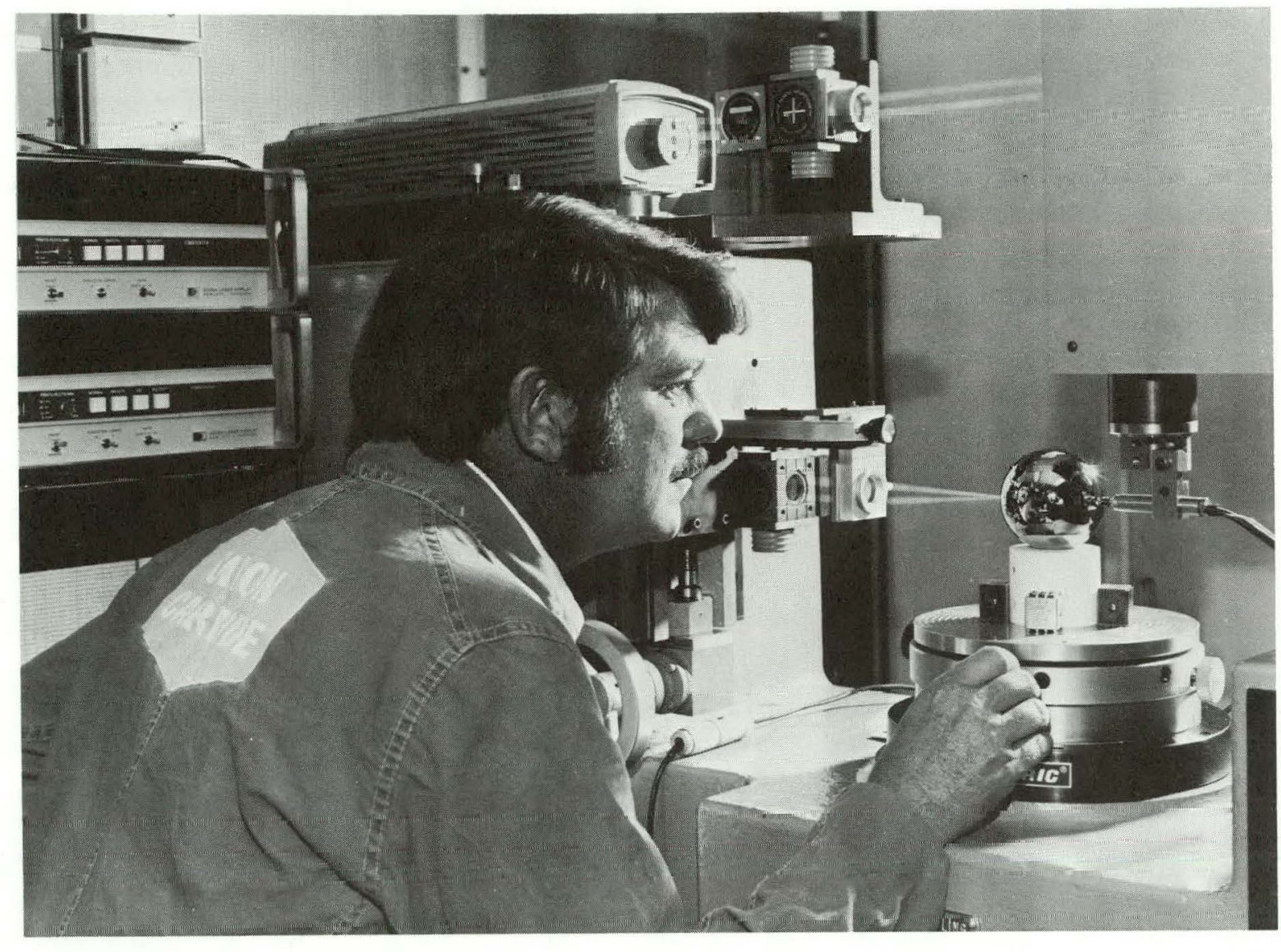

Figure 2. NONCONTACT, LASER INTERFEROMETER SWEEP GAGE.

precision inspection machine utilizes two laser channels to measure size and contour of reflective diamond-turned parts. The beam from the Hewlett-Packard Model 5500C laser head is directed to a Model 10567A beam splitter and on to separate interferometers. The upper beam is sent to a Model 10565B remote interferometer with a Model 10581A plane-mirror converter and on to a plane mirror. (A Model K05-5505A modified resolution board is added to the Model 5505A laser display to correct the readout for the inherent resolution doubling.) The lower beam is sent to another remote interferometer and focused onto the surface of the reflective part. The upper beam determines the position of the linear quill slide that supports the linear-variable-differential-transformer (LVDT) gage head used to master the gage, while the lower beam detects perturbations in the surface of the diamond-turned part. Part-certification data are obtained with a $15 \mathrm{~nm}(0.6 \mu \mathrm{in})$ resolution from the up/down pulse-output information generated by the optional pulse/quadrature 
board in the display. The pulses are accumulated in a counter and used to drive a polar recorder associated with the air-bearing rotary table. Both axes have auxiliary Model K04-59995A resolution extenders wired for 10X operation. (A Model K03-10565A single-beam interferometer could also have been used in place of the lower, remote interferometer; but not all resolution extender/single-beam interferometer combinations allow stable operation.)

Figure 3 shows an example of a laser interferometer used in a machine-tool control system. In this instance, the machine is run in an open-loop mode due to backlash in the slide-drive gearing. The feedback information is utilized in the minicomputer residing in the NC to alter the axis command signal to account for deviations between the actual and the programmed tool paths (slide-position errors are encountered as a result of cyclic errors in the slide-drive gearing). Compensation is achieved by adding or subtracting pulses to the interpolatorgenerated pulse train that is sent to the motor-drive electronics. (b) Figure 4 shows a close-up

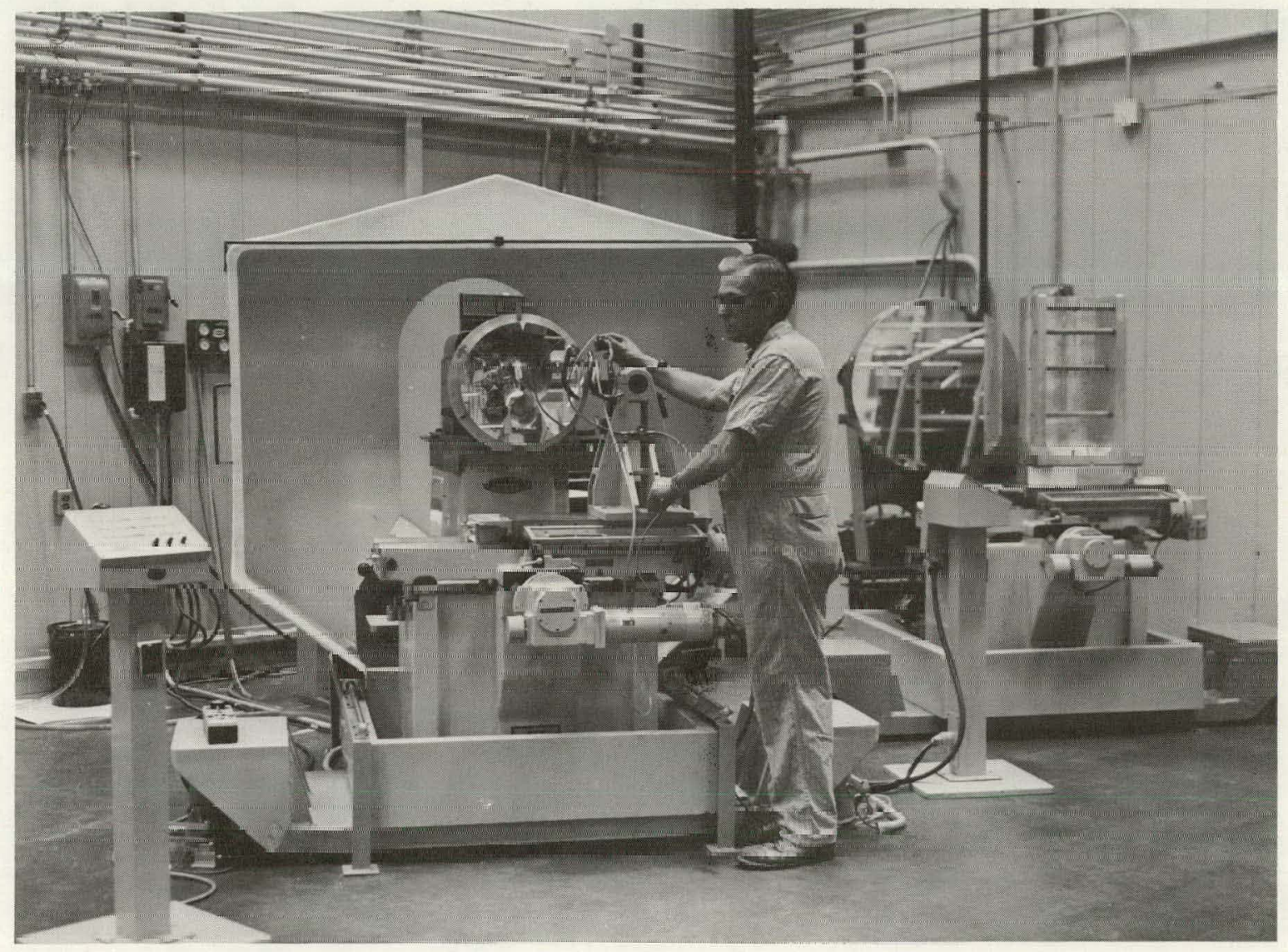

Figure 3. SMALL PRODUCTION MACHINE TOOL WITH LASER INTERFEROMETER.

(b) Burleson, R. R.; Laser-Error-Correction Control Unit for Machine Tools, Y-2129; Union Carbide Corporation-Nuclear Division, Oak Ridge Y-12 Plant, Oak Ridge, Tennessee; May 23, 1978. 


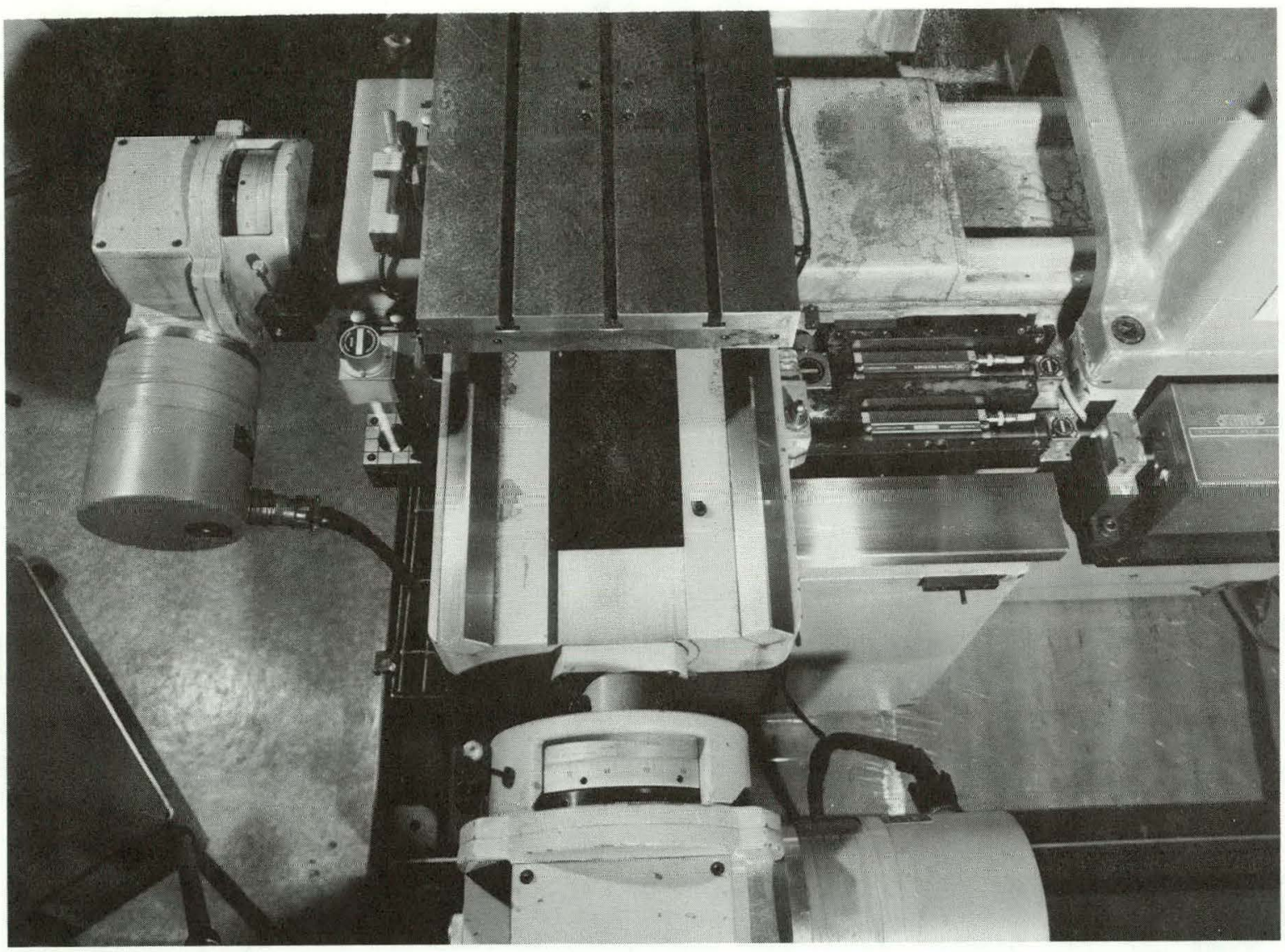

176762

Figure 4. LAYOUT OF LASER OPTICS ON MACHINE TOOL.

view of the machine slides and the Hewlett-Packard Model 5501 laser transducer system. Both axes on this machine utilize Model 10702A linear interferometers, Model 10703A retroreflectors, Model 10707A beam benders, and Model 10780 receivers. One Model $5501 \mathrm{~A}$ laser transducer is used with a Model 10701A beam splitter to provide 2-axis operation. The system electronics use a Model 10781 A pulse converter to provide nominal $15 \mathrm{~nm}(0.6 \mu \mathrm{in})$ displacement information to the minicomputer. Environmentalcompensation adjustments to these data are also performed in the computer. Another option currently available is to utilize the Model 10760A counter and the 10763A English/metric pulse-output board combination to provide compensated $25 \mathrm{~nm}$ ( $1 \mu \mathrm{in}$ ) output data to the NC. Figures 5 and 6 demonstrate the improvement in tool path obtained with this type of laser feedback and various "error bounds" (error limits at which corrective action was taken based on the laser-feedback signal).

Figure 7 shows another machine tool that incorporates laser feedback into a more conventional closed-loop servo system. Initially, this machine was configured with the Model 5526 cross-slide laser mounted at about the same elevation as the machine slideways, while the work-slide laser was mounted at spindle centerline. Unfortunately, mechanical stability problems were encountered that made this layout unacceptable. The present 

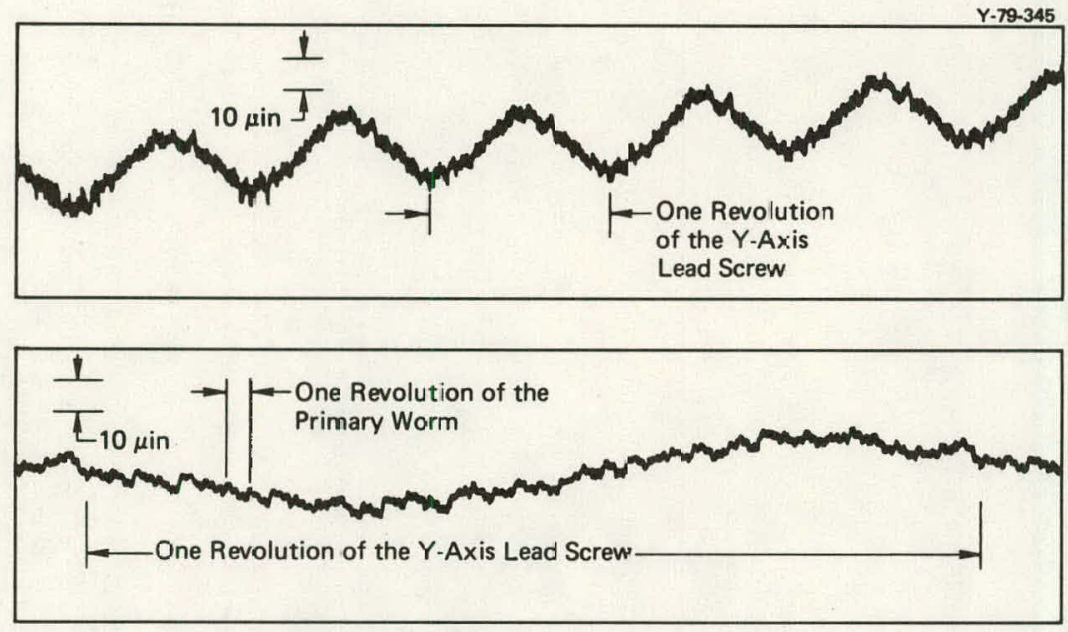

(a) Cyclic Positional Errors Correspond to Revolutions of Drive Train Components.

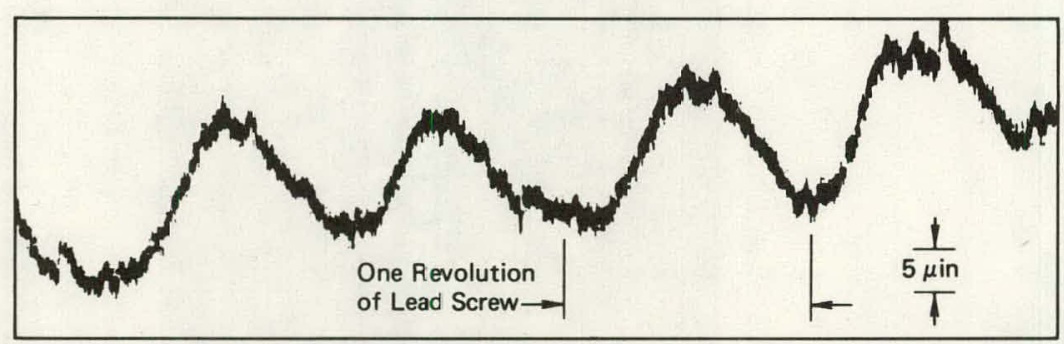

(b) Dynamic Errors at Positioning Laser Height anc Correction Error Bound at $\pm 10 \mu \mathrm{in}$. Figure 5. LEAD SCREW CYCLE ERRORS.

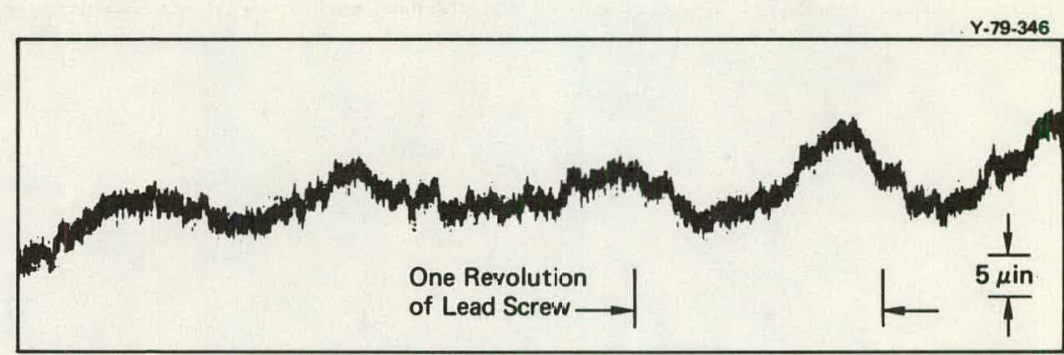

(a) Dynamic Errors at Positioning Laser Height and Correction Error Bound at $\pm 4 \mu \mathrm{in}$

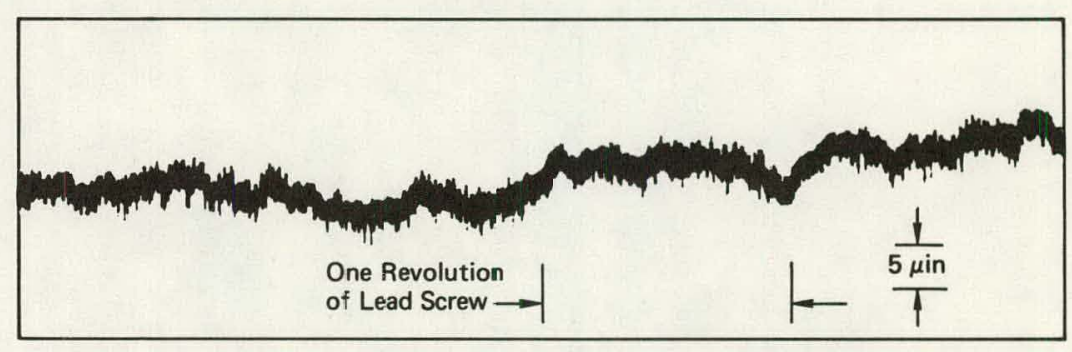

(b) Dynamic Errors at Positioning Laser Height and Correction Error Bound at $\pm 1 \mu \mathrm{in}$

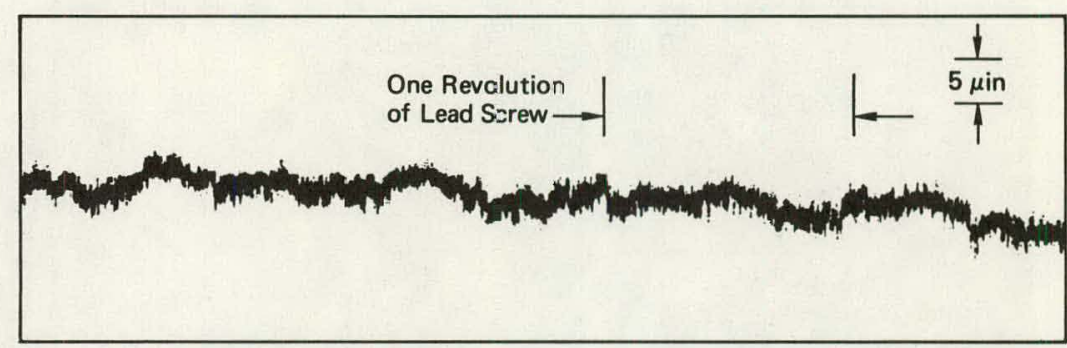

(c) Dynamic Errors at Tool Height and Ccrrection Error Bound at $\pm 1 \mu$ in

Figure 6. REDUCTION OF CYCLE ERROR THROUGH LASER FEEDBACK. 


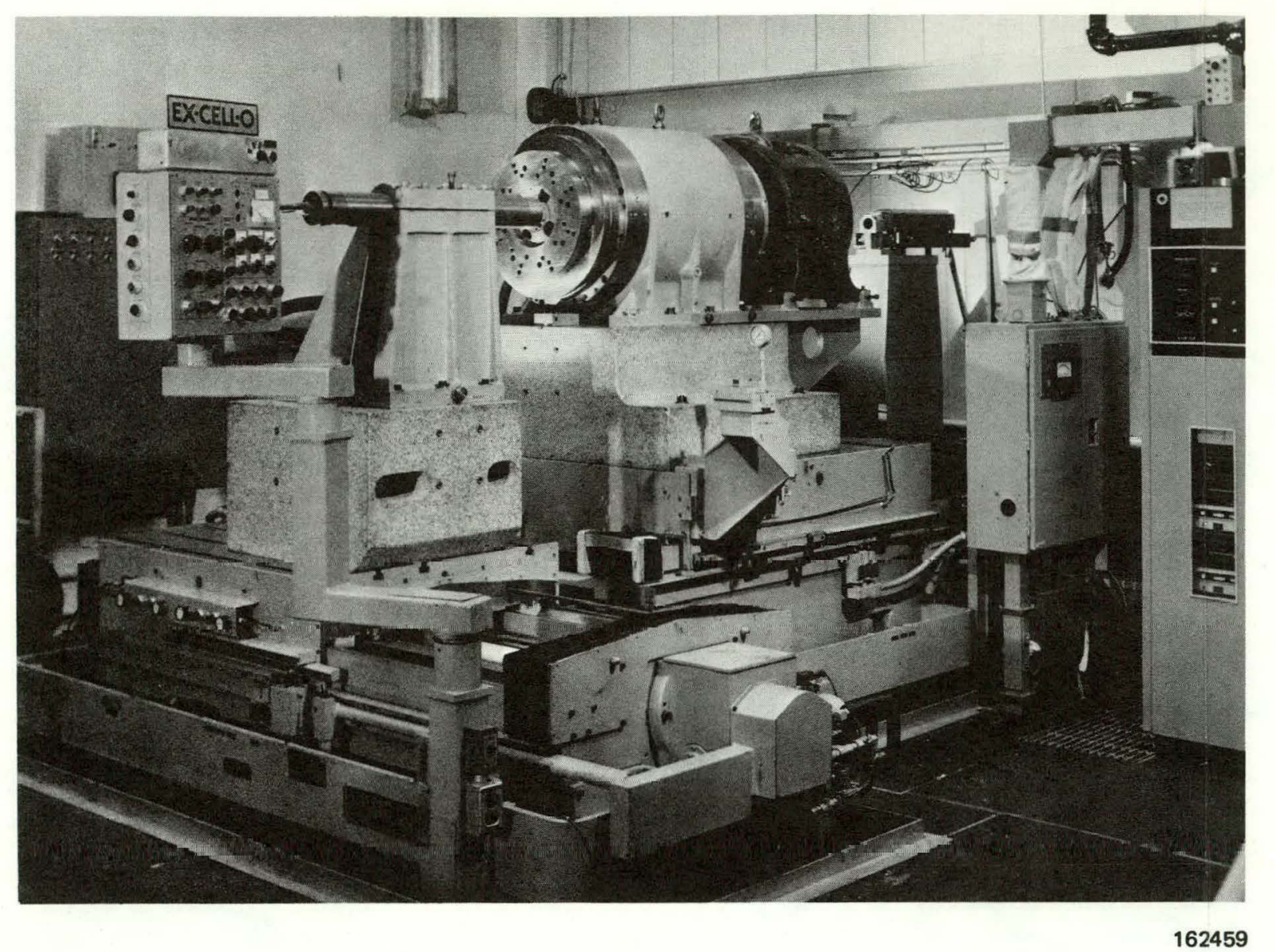

Figure 7. LARGE PRODUCTION MACHINE USED FOR DIAMOND TURNING.

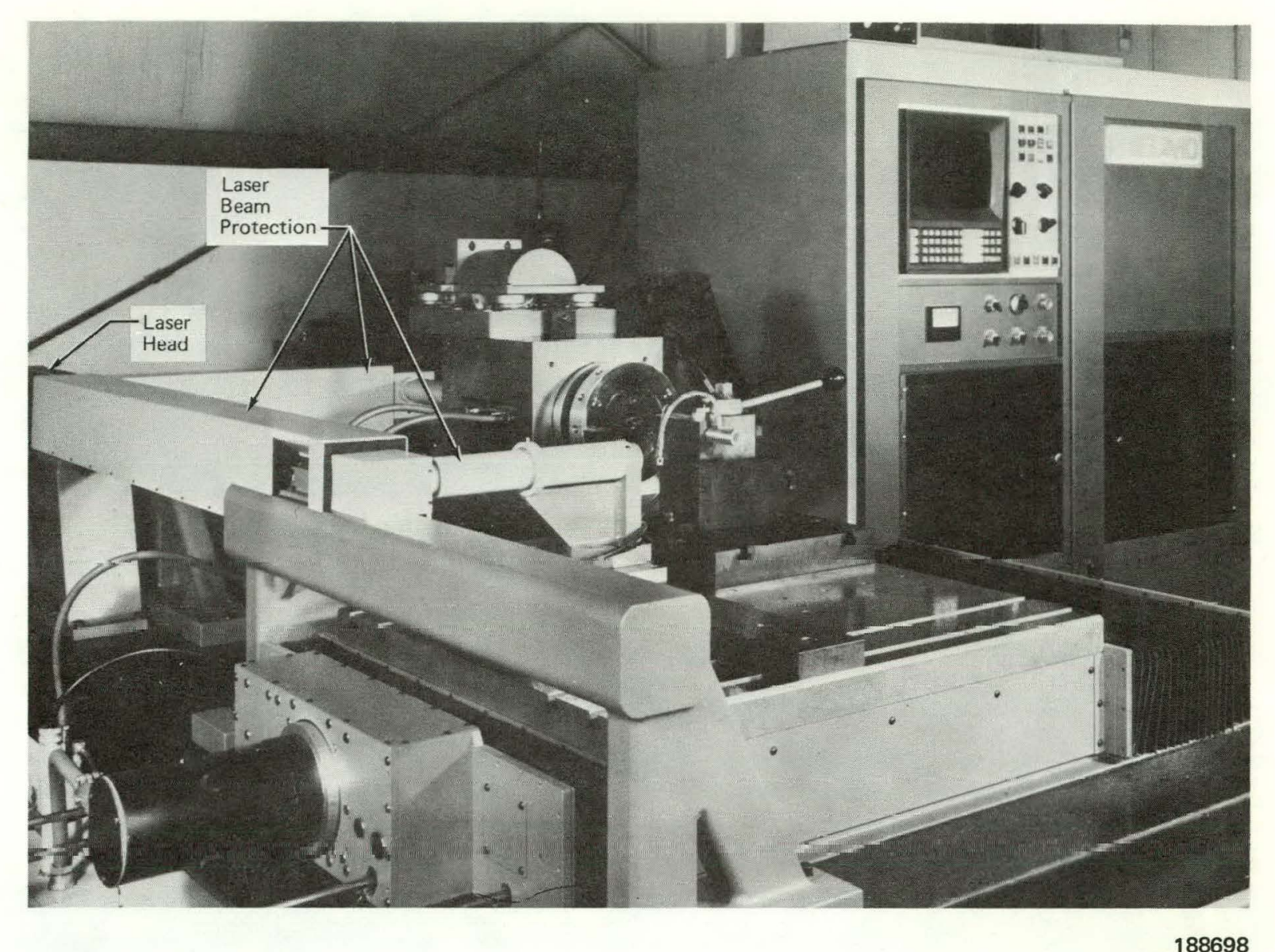

Figure 8. PNEUMO PRECIIION, INC MACHINE TOOL WITH LASER FEEDBACK. (Photograph courtesy of Preumo
Precision Inc, Keene, NH)

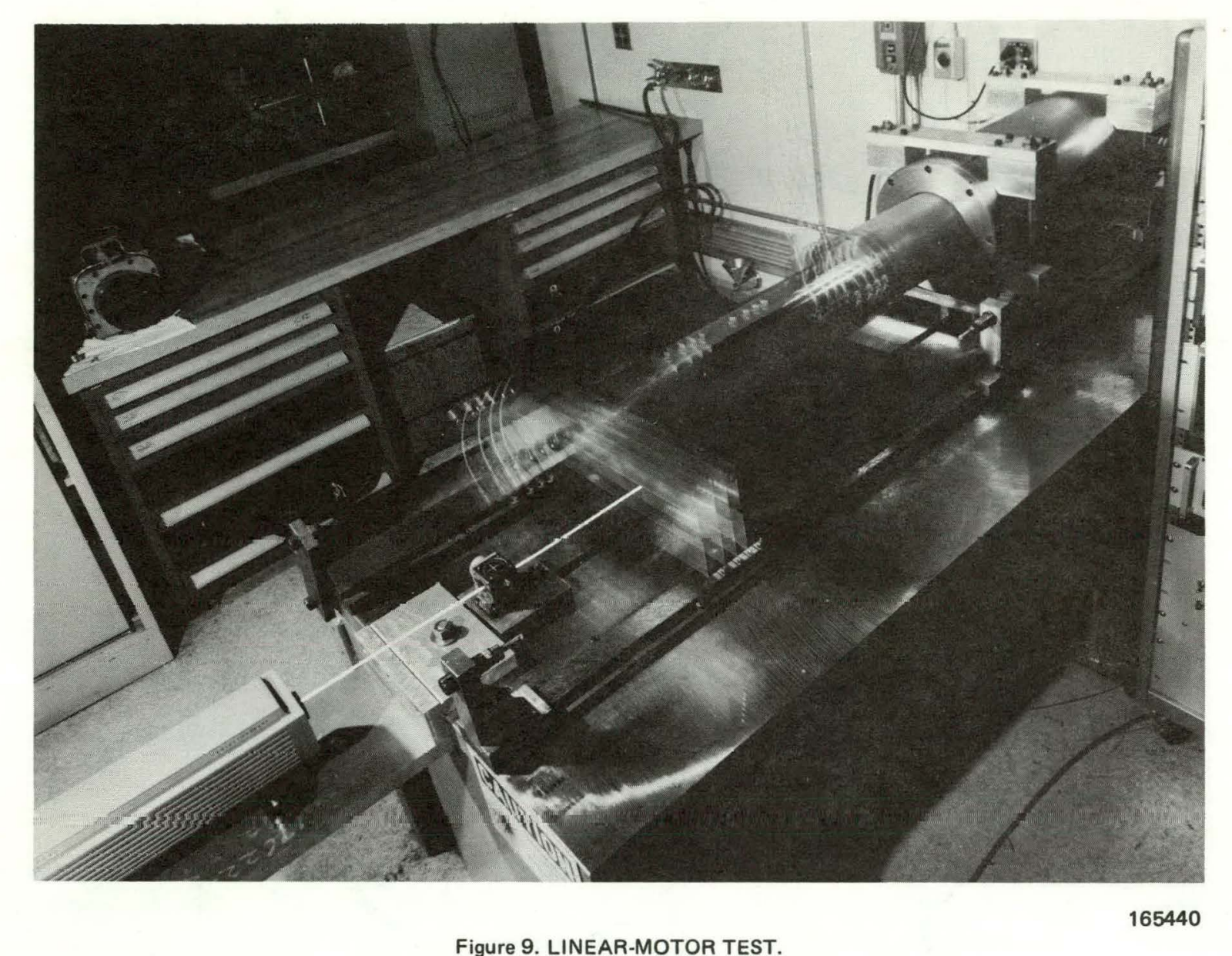

Figure 9. LINEAR-MOTOR TEST.

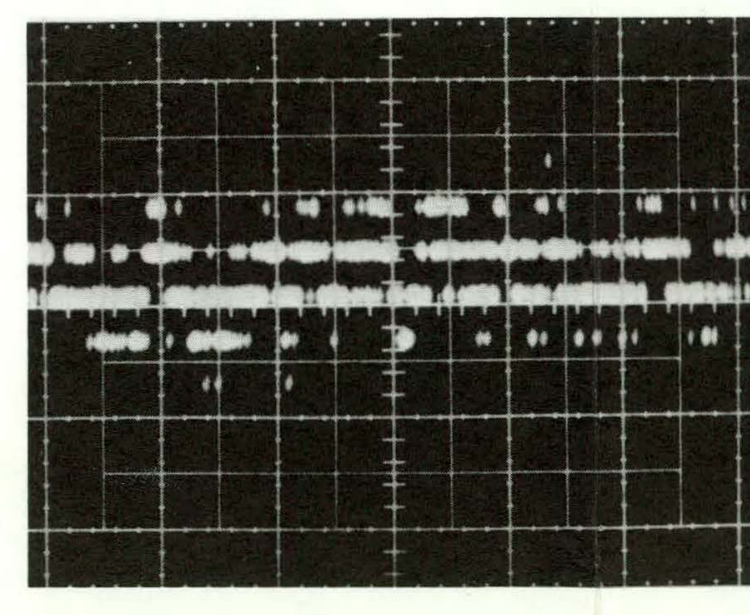

(a) $5 \mathrm{~mm} / \mathrm{min}(0.2 \mathrm{in} / \mathrm{min})$

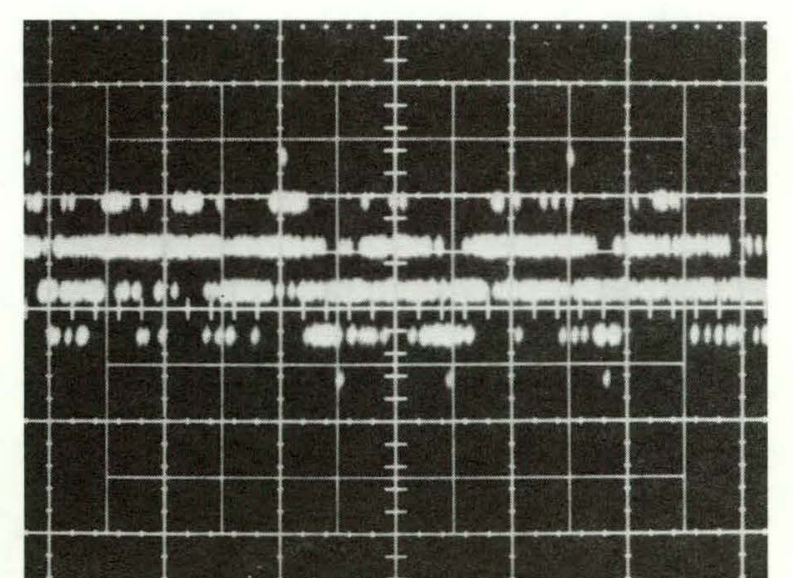

(b) $13 \mathrm{~mm} / \mathrm{min}(0.5 \mathrm{in} / \mathrm{min})$

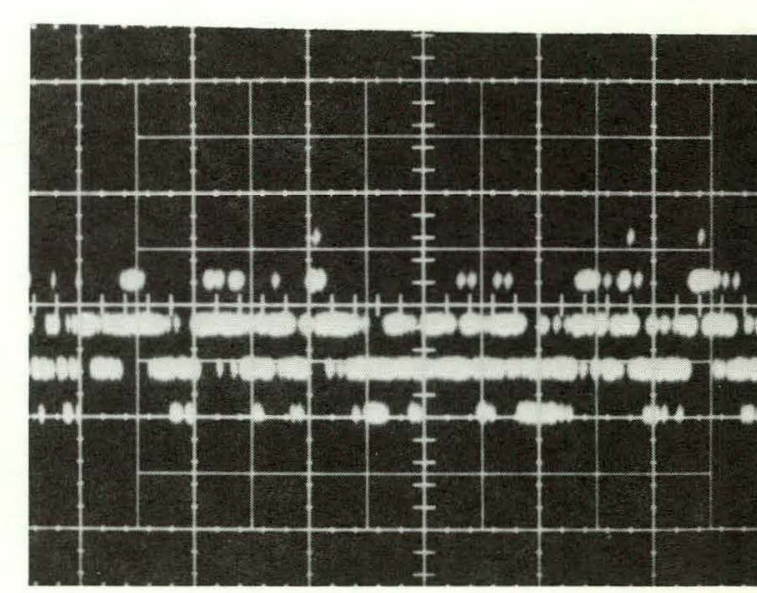

(c) $25 \mathrm{~mm} / \mathrm{min}(1 \mathrm{in} / \mathrm{min})$

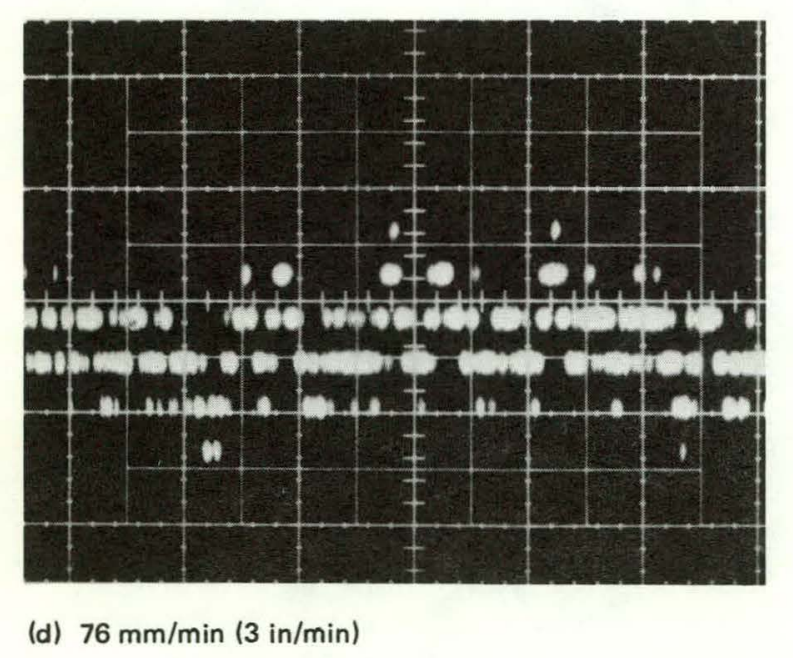


configuration consists of a single laser head which is mounted at slide height, a beam splitter, two remote interferometers, and two retroreflectors. Since spindle growth is no longer being sensed by the work-slide laser, it is now necessary to incorporate a spindle-warm-up period into the machining cycle. However, an advantage is that the reference locations for both axes are now close together and less sensitive to the thermal stability of the machine base. Displacement information is provided to the NC with a nominal resolution of $15 \mathrm{~nm}(0.6 \mu \mathrm{in})$ by $A$-quad-B output data from the laser display. Wavelength of light compensation is implemented in hardwired circuitry within the control.

Figure 8 shows a precision diamond-turning lathe manufactured by Pneumo Precision in Keene, New Hampshire. This machine utilizes the Model 5501 laser transducer system to provide A-quad-B pulse output data to the encoder input of a computer-numerical-control $(\mathrm{CNC})$ system. This layout incorporates a single laser head that is located at the rear of the machine. Work-slide position is measured at spindle centerline while cross-slide position is measured at tool height. Initial stability problems were encountered owing to vibration in the laser beam-path brackets, but the subsequent addition of damping resulted in excellent system operation with $25 \mathrm{~nm}(1 \mu \mathrm{in})$ resolution feedback.

Figure 9 shows a Model 5526 laser system mounted on a test bed used to develop linear-motor drive systems. In this application, the laser head is mounted on a rather flimsy bracket outboard to the tabletop. This does not cause a problem because the remote interferometer is mounted rigidly to the tabletop, and any relative motion occuring between the laser head and remote interferometer is revealed in both the reference and measurement paths. Pulse-data output from the laser display is used to close the position servo loop through a dedicated microcomputer, while the F/V circuitry shown earlier in Figure 1 is used to provide an analog rate signal.

Extensive tests have been conducted with this system using laser-feedback resolution values between $2-150 \mathrm{~nm}(0.08-6 \mu \mathrm{in})$. No attempt has been made to correct for environmental factors since system operation can be accurately characterized over relatively small displacements. System performance is evaluated by examining the ripple on the miciuconiluter-calculated following-error signal. Figure 10 shows a typical set of test results for a system resolution of. $2.5 \mathrm{~nm}(0.1 \mu \mathrm{in})$. 


\section{CONCLUSIONS}

The laser-interferometer position transducer is a versatile, accurate, easily used instrument. In comparison with conventional position transducers, the only disadvantage is its higher cost, while its advantages make it the only adequate device in many precision applications. The future development of lessexpensive laser tubes should result in more wide-spread usage. Present systems offer an accuracy of $\pm 0.5 \mathrm{ppm}$ with a velocity limit of $18 \mathrm{~m} / \mathrm{min}$ $(720 \mathrm{in} / \mathrm{min})$. Electronic resolution extension is available to divide the $150 \mathrm{~nm}(6 \mu \mathrm{in})$ pulse value by factors as large as $40 X$, and use of the plane-mirror interferometer allows an effective resolution extension of $80 \mathrm{X}$. Unfortunately, resolution extension also proportionally lowers the maximum tolerable velocity because the electronics have a fixed data-processing capability. In addition, resolution extension may not be compatible with all single-beam interferometers; so this combination should be avoided whenever possible.

Other factors to consider in planning the system include wavelength of light compensation, dead-path compensation, and Abbé offsets. The wavelength compensation can be handled by manual or automatic means, while the dead path can be minimized at the design stage as well as by using electronic compensation. Abbé offsets can also be reduced during the initial design phase, but it is frequently difficult to locate the laser beam precisely at the most desirable point. In this instance, efforts should be made to obtain a "loop" that is as small and as stable as possible between the point of measurement and the point of interest (such as the tip of a cutting tool). A stable mounting system for the laser optics is an absolute requirement to avoid measurement errors, and careful alignment procedures must be followed during the setup period to ensure that the beam direction and slide travels are parallel in order that cosine errors are avoided.

Finally, other laser optics and accessories exist, such as the angular/flatness interferometer, the straightness interferometer, and calculator options that permit the user to run diagnostic measurements on machine tools. When combined with the plotting options, this equipment can be a valuable aid in setting up the precision machine tool. 


\section{Distribution}

Department of Energy - Oak Ridge

Hickman, H. D:

Leed, R. E.

Poteat, R. M.

Lawrence Livermore Laboratory

Arnold, W. F.

Los Alamos Scientific Laboratory

Hoyt, H. C.

Oak Ridge Gaseous Diffusion Plant

Armstrong, R. C.

Stief, S. S:

Wilcox, W. J., Jr

Oak Ridge National Laboratory

Hopkins, C. C.

Oak Ridge Y-12 Plant

Alvey, H. E.

Anderson, P. J.

Barkman, W. E. (35)

Dawson, D. $\mathrm{O}$.

Dodson, W. H./Googin, J. M.

Douglass, S. S.

Fraser, R. J.

Gerth, H. L.

Hewgley, F. E., Jr

Hurst, J. S.

Keith, A.

Kite, H. T. (30)

Mills, J. M., Jr

Miskell, R. V.

Phillips, L. R.

Steger, P. J.

Thompson, C. H.

Tunnell, H. A.

Whitten, L. G., Jr

Wright, C. C.

Y-12 Central Files (master copy)

$Y=12$ Central riles (route copy)

$Y-12$ Central Files ( $Y$-12RC)

$Y-12$ Central Files (5)
Paducah Gaseous Diffusion Plant

Bewley. H. D.

Pneumo Precision, Inc.

Brehm, J. H.

Sandia - Livermore

Spencer, W. J.

Union Carbide Corporation - New York

Tinsley, S. W.

In addition, this report is distributed in accordance with the Category UC-38, Engineering and Equipment, as given in the Standard Distribution for Unclassificd Scicntific and Technical Reports, DOE/TIC-4500. 